\title{
Effect of calcination temperature on the properties of CZTS absorber layer prepared by RF sputtering for solar cell applications
}

\author{
Sachin Rondiya ${ }^{1} \cdot$ Avinash Rokade $^{1} \cdot$ Ashok Jadhavar $^{1} \cdot$ Shruthi Nair $^{1}$ • \\ Madhavi Chaudhari $^{1} \cdot$ Rupali Kulkarni $^{1} \cdot$ Azam Mayabadi $^{1} \cdot$ Adinath Funde $^{1}$. \\ Habib Pathan ${ }^{2} \cdot$ Sandesh Jadkar ${ }^{2}$
}

Received: 16 November 2016/Accepted: 12 April 2017/Published online: 19 April 2017

(c) The Author(s) 2017. This article is an open access publication

\begin{abstract}
In present work, we report synthesis of nanocrystalline Kesterite copper zinc tin sulfide (CZTS) films by RF magnetron sputtering method. Influence of calcination temperature on structural, morphology, optical, and electrical properties has been investigated. Formation of CZTS has been confirmed by XPS, whereas formation of Kesterite-CZTS films has been confirmed by XRD, TEM, and Raman spectroscopy. It has been observed that crystallinity and average grain size increase with increase in calcination temperature and CZTS crystallites have preferred orientation in (112) direction. NC-AFM analysis revealed the formation of uniform, densely packed, and highly interconnected network of grains of CZTS over the large area. Furthermore, surface roughness of CZTS films increases with increase in calcination temperature. Optical bandgap estimated using UV-Visible spectroscopy decreases from $1.91 \mathrm{eV}$ for as-deposited CZTS film to $1.59 \mathrm{eV}$ for the film calcinated at $400{ }^{\circ} \mathrm{C}$ which is quite close to optimum value of bandgap for energy conversion in visible region. The photo response shows a significant improvement with increase in calcinations temperature. The employment these films in solar cells can improve the conversion efficiency by reducing recombination rate of photo-generated charge carriers due to larger grain size. However, further detail study is needed before its realization in the solar cells.
\end{abstract}

Sandesh Jadkar

sandesh@physics.unipune.ac.in

1 School of Energy Studies, Savitribai Phule Pune University, Pune 411 007, India

2 Department of Physics, Savitribai Phule Pune University, Pune 411 007, India
Keywords CZTS films · RF sputtering - Kesterite · Calcination $\cdot$ XRD, XPS, NC-AFM

\section{Introduction}

As on today, silicon ( $\mathrm{Si}$ ) has the lion's share in the photovoltaic industry. The main reason behind it is the huge availability of $\mathrm{Si}$ on the earth and a developed and established industry for making high-quality $\mathrm{Si}$ solar cells. However, the cost of Si solar cells is still high due to the high production cost of device quality Si. The photovoltaic market nowadays is demanding low production cost of material and hence of solar cells [1]. Therefore, it is necessary to reduce the material cost of solar cells which effectively reduces the cost of solar cells [2]. Several other direct bandgap semiconductor materials, such as copper indium gallium sulfides (CIGS), cadmium telluride (CdTe), etc, have been tried for solar cell application. However, these materials have their own problems like $\mathrm{Cd}$ and $\mathrm{Te}$ which are toxic, while $\mathrm{Ga}$ and In are expensive, which restrict the future development of solar cells. Copper zinc tin sulfide $\left(\mathrm{Cu}_{2} \mathrm{ZnSnS}_{4}\right)$ or simply CZTS is one of the promising absorber materials in thin-film solar cell because of its excellent material properties for obtaining high efficiency such as direct bandgap (1.45 eV) [3], which is very close to optimum bandgap for solar energy conversion, high absorption coefficients $\left(>10^{4} \mathrm{~cm}^{-1}\right)$ [4], etc. In addition, CZTS does not contain any toxic and expensive element, resulting in realizing of solar cell with less environmentally damaging and low cost. It is composed of naturally abundant and nontoxic elements [5]. The maximum theoretical power conversion efficiency of CZTS solar cells reported was $29.4 \%$ [6]. Wang and his group fabricated laboratory scale CZTSSe solar cell having area 
$0.42 \mathrm{~cm}^{2}$ with efficiency $12.6 \%$, which is the highest conversion efficiency achieved until today [7].

There are two methods used for the preparation of CZTS films, chemical methods, and physical/vacuum-based methods. The chemical methods include several techniques, such as chemical spray pyrolysis [8], photochemical depositions [9], sol-gel technique [10], spin coating [11], electrodeposition [12], electro-spinning [13], and successive ionic layer adsorption and reaction (SILAR) [14], etc. The physical or vacuum-based method includes atom beam sputtering [15], e-beam and thermal evaporation [16], pulsed laser deposition [17], etc. Each method has its own advantages and limitations. Among these methods, RF magnetron sputtering has received considerable attention in recent years owing to its capability to synthesize device quality CZTS films. It permits deposition at low substrate temperature, gives the good adhesion, possibility of large area deposition, maximum uniformity, controllable thickness, precise in chemical composition control, matching with tradition solar cell production line, as well as easy scale-up than other CZTS thin-film deposition methods [18].

Properties of CZTS thin films are greatly influenced by pre- and post-annealing or calcinations treatment in various gas atmospheres. Recently, small work has been done on effect of pre- and post-annealing or calcinations treatment in various gas atmospheres on structural, optical, and electrical properties of CZTS thin films deposited by various methods. Recently, Seboui et al. [19] investigated post growth effect on properties of CZTS thin films prepared by spray pyrolysis and reported that the post-annealing effect reduces the optical transmission and increases the bandgap of CZTS films. Secondary phases may remain in the film after heat treatment. Ericson et al. [20] obtained highly crystalline CZTS films after annealing in $\mathrm{H}_{2} \mathrm{~S}$ atmosphere. Surgina et al. [21] have also studied the annealing effect on structural and optical properties of CZTS films grown by pulsed laser deposition in $\mathrm{N}_{2}$ atmosphere. Vanalakar et al. [22] explained the post-annealing effect on grain size and surface morphology of CZTS thin films in the different gas atmospheres. Recently, Liu et al. [23] reported preheating effect on CZTS film properties. Most of the authors reported the effect of pre- or post-annealing of CZTS films either at high temperature or in presence of toxic or hazardous gases. To best of our knowledge, low temperature calcination of CZTS in inert gas atmosphere is missing till date. With this motivation an attempt has been made to investigate low post calcination effect $\left(>400{ }^{\circ} \mathrm{C}\right)$ in inert gas (Ar) atmosphere on structural, optical, morphology and electrical properties of CZTS thin films deposited by RF magnetron sputtering. It has been observed that by increasing calcination temperature in $\mathrm{Ar}$ atmosphere, it is possible to grow highly uniform, large area $\left(\sim 4 \mathrm{~cm}^{2}\right)$ nanocrystalline kesterite-CZTS films with optimum bandgap $(\sim 1.59 \mathrm{eV})$ which can be useful for enhancing the efficiency of CZTS solar cells.

\section{Experimental details}

\section{Film preparation and calcination}

CZTS films were deposited on corning \#7059 substrates using indigenously design and locally fabricated RF magnetron sputtering technique. It consists of a cylindrical stainless steel chamber (process chamber) coupled with a turbo molecular pump (TMP) followed by a roughing pump which yields a base pressure less than $10^{-7}$ Torr. A target (Cu:Zn:Sn:S of 1.1:1.1:1.1:3) of 4 inch diameter (99.99\%, RND-KOREA, Korea), $3 \mathrm{~mm}$ thick was used for the deposition of CZTS films and was kept facing the substrate holder $\sim 9 \mathrm{~cm}$ away. In order to get film uniformity substrates were kept rotating during the sputtering process using a stepper motor at a rate $12 \mathrm{rpm}$ using speed controller. The substrate temperature was kept constant at $100{ }^{\circ} \mathrm{C}$ using the in-built thermocouple and temperature controller. The substrates can be clamped on the substrate holder which is heated by in-built heater using thermocouple and temperature controller. The pressure during deposition was kept constant by using automated throttle valve and measured with the capacitance manometer. For sputtering argon gas was introduced into the process chamber through a specially designed gas bank assembly which consists of mass flow controllers (MFCs) and gas mixing. The process parameters employed during the deposition of CZTS films are listed in Table 1.

Before each deposition the substrates were cleaned using a standard cleaning procedure using piranha solution. Prior to deposition, the substrate holder and deposition chamber were baked for two hours at $100{ }^{\circ} \mathrm{C}$ to remove any water vapor absorbed on the substrates and to reduce the oxygen contamination in the film. Sputter-etch of 10 min were used to remove the target surface contamination. As-deposited CZTS films then calcinated at different temperatures in argon atmosphere for $90 \mathrm{~min}$ in a cylindrical stainless steel chamber without air-break. During calcination the argon flow rate and pressure were kept constant at $50 \mathrm{sccm}$ and $20 \mathrm{mTorr}$ respectively. After calcination films were allowed to cool to room temperature in vacuum and then taken out for characterization.

\section{Film characterization}

X-ray diffraction patterns were obtained by X-ray diffractometer (Bruker D8 Advance, Germany) using $\mathrm{CuK} \alpha$ line $(\lambda=1.54 \AA)$ at a grazing angle of $1^{\circ}$. Raman spectra were 
Table 1 Process parameters employed during the deposition of CZTS films

\begin{tabular}{ll}
\hline Process parameter & Value \\
\hline Deposition pressure & $6 \times 10^{-3}$ bar \\
Deposition time & $60 \mathrm{~min}$ \\
RF power & $100 \mathrm{~W}$ \\
Distance between substrate holder and target electrode & $9 \mathrm{~cm}$ \\
Ar gas flow rate & $60 \mathrm{sccm}$ \\
Substrate temperature & $100{ }^{\circ} \mathrm{C}$ \\
\hline
\end{tabular}

recorded in the range of $100-600 \mathrm{~cm}^{-1}$. The spectrometer has the back-scattering geometry for detection of Raman spectrum with the resolution of $1 \mathrm{~cm}^{-1}$. The excitation source was $532 \mathrm{~nm}$ line of $\mathrm{He}-\mathrm{Ne}$ laser. The power of the Raman laser was kept less than $5 \mathrm{~mW}$ to avoid laser-induced crystallization of the film. The HR-TEM and SAED patterns were recorded using TECNAI G2-20-TWIN, transmission electron microscope operating at $200 \mathrm{kV}$. The optical bandgap of CZTS was deduced from absorbance spectra and was measured using a JASCO, V-670 UVVisible spectrophotometer. The surface topology of the films was investigated NC-AFM (JEOL, JSPM-5200). The XPS spectra were recorded using a VSW ESCA instrument with a total energy resolution $\sim 0.9 \mathrm{eV}$ fitted with an $\mathrm{Al}$ $\mathrm{K} \alpha$ source (soft X-ray source at $1486.6 \mathrm{eV}$ ) at base vacuum $>10^{-9}$ Torr. The XPS signal was obtained after several scans in the acquisition process. The spectra were recorded for the specific elements $(\mathrm{Cu}, \mathrm{Zn}, \mathrm{Sn}, \mathrm{S})$. The photo response measurement of the CZ TS films was studied using a Keithley 2401 system. For light illumination, a PEC-L01 Portable Solar Simulator was used. Thickness of films was determined by profilometer (KLA Tencor, P-16+).

\section{Results and discussion}

\section{X-ray diffraction (XRD) analysis}

Figure 1 show the low angle-XRD pattern of as-deposited and calcinated CZTS films. As seen from the XRD pattern, as-deposited and calcinated CZTS film at $200{ }^{\circ} \mathrm{C}$ show only a diffraction peak at $2 \theta \sim 28.65^{\circ}$. The CZTS film calcinated at $300{ }^{\circ} \mathrm{C}$ shows a tiny diffraction peak at $2 \theta \sim 31.83^{\circ}$ along with a diffraction peak at $2 \theta \sim 28.65^{\circ}$. At $400{ }^{\circ} \mathrm{C}$, the $\mathrm{x}$-ray diffraction pattern shows three diffraction peaks at $2 \theta \sim 28.65^{\circ}, 31.83^{\circ}$ and $58.98^{\circ}$ which are corresponding to (112), (200) and (224) planes of the kesterite-CZTS structure [JCPDS data card\# 26-0575]. No peak of any other phase was found in XRD pattern. With increase in calcination temperature intensity of (112)

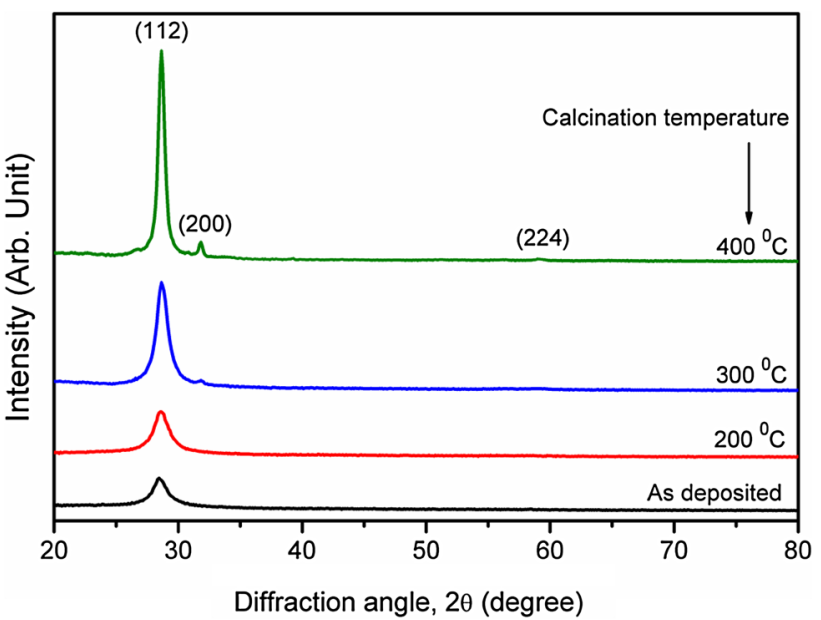

Fig. 1 XRD pattern of as-deposited and after calcination CZTS thin films at different temperatures for kesterite-CZTS crystal structure [JCPDS data card \# 26-0575]

diffraction peaks increases whereas its sharpness gets reduced. The peak at $2 \theta \sim 28.65^{\circ}$ has highest intensity among all other peaks which indicate that CZTS crystallites have preferred orientations in (112) direction. The average grain (dx-ray) size has been estimated using the classical Scherer's formula [24],

$d_{\mathrm{x}-\mathrm{ray}}=\frac{0.9 \lambda}{\beta \cos \theta_{\beta}}$

where $\lambda$ is the wavelength of the $\mathrm{x}$-ray used, $\beta$ is full-width at half-maximum (FWHM) and $\theta$ is the Bragg diffraction angle. The average microstrain $(\varepsilon)$ developed in the asprepared and calcinated CZTS films was calculated by using the relation [25],

$\varepsilon=\frac{\beta \cos \theta}{4}$

The calculated structural parameters are presented in Table 2. As seen from Table 2, the average grain size of CZTS films increases with increasing calcination temperature. This may be due to coalescence and reorganization of grains with increase in calcination temperature. It is further supported by observed decrease in macrostrain with increase in calcination temperature. The coalescence and reorganization of grains fill voids due to calcination and the film become denser. The atomic force microscopy (AFM) analysis further supports this conjecture (discussed later).

\section{Raman spectroscopy analysis}

Figure 2 shows Raman spectra of as-deposited and calcinated CZTS films in the range $100-600 \mathrm{~cm}^{-1}$. As seen for as-deposited film the dominant Raman peak is observed at $\sim 338 \mathrm{~cm}^{-1}$ which is in consistent with the peak of CZTS mono-grain powder reported in literature [26]. With 
Table 2 Structural parameters, average grain size $\left(d_{\mathrm{x}-\mathrm{ray}}\right)$, full-width half-maxima (FWHM), inter-planar spacing $\left(d_{\mathrm{hkl}}\right)$, and microstrain $(\varepsilon)$ for CZTS films

\begin{tabular}{lllll}
\hline Calcination temperature $\left({ }^{\circ} \mathrm{C}\right)$ & $d_{\mathrm{x}-\mathrm{ray}}(\mathrm{nm})$ & FWHM $\left({ }^{\circ}\right)$ & $d_{\mathrm{hkl}}(\AA)$ & \\
\hline As deposited & 7.66 & 1.07 & 3.20 & $4.23 \times 10^{-3}$ \\
200 & 7.67 & 1.07 & 3.12 & $4.52 \times 10^{-3}$ \\
300 & 10.52 & 0.78 & 3.11 & $3.29 \times 10^{-3}$ \\
400 & 16.83 & 0.49 & 3.11 & $2.06 \times 10^{-3}$ \\
\hline
\end{tabular}

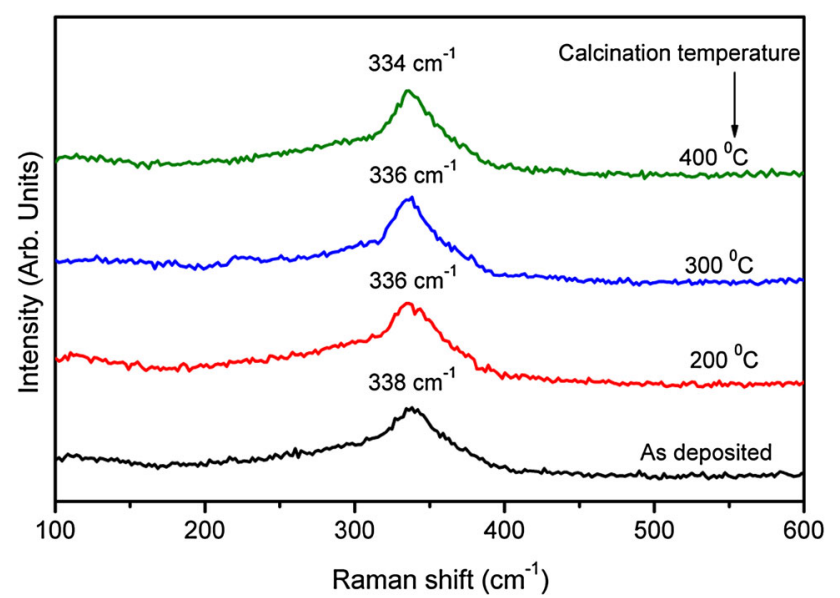

Fig. 2 Raman spectrum of kesterite CZTS of as deposited and after calcination CZTS thin films at different temperatures. The observed featured peaks are at 344,336 , and $338 \mathrm{~cm}^{-1}$ and indicates that CZTS has synthesized without any impurity phases

an increase in calcination temperature the Raman peak shift towards lower wavenumber. Thus, CZTS film calcinated at $400{ }^{\circ} \mathrm{C}$, show the Raman peak $\sim 334 \mathrm{~cm}^{-1}$. The presence of internal compressive stress may responsible for shifting of Raman peak towards lower wavenumber. In addition, shrinking of substrate while cooling may also contribute to the internal strain in CZTS film [27]. The presence of the internal strain has been confirmed by low angle-XRD analysis (See Table 2). Normally, the main Raman peaks from the different phases potentially present in CZTS system are $\mathrm{CuS}\left(\sim 267 \mathrm{~cm}^{-1}\right), \mathrm{SnS}\left(\sim 220 \mathrm{~cm}^{-1}\right), \mathrm{SnS}_{2}$ $\left(\sim 202 \mathrm{~cm}^{-1}\right), \mathrm{Sn}_{2} \mathrm{~S}_{3}\left(\sim 234 \mathrm{~cm}^{-1}\right), \mathrm{ZnS}\left(\sim 219 \mathrm{~cm}^{-1}\right)$, $\mathrm{Cu}_{2} \mathrm{SnS}_{3}\left(\sim 290 \mathrm{~cm}^{-1}\right)$ and $\mathrm{Cu}_{2} \mathrm{ZnSnS}_{4}\left(\sim 337 \mathrm{~cm}^{-1}\right)$ [28].However, in present study, we have observed only a Raman peak in the range $334-338 \mathrm{~cm}^{-1}$ suggesting the existence of single phase CZTS films. Low angle-XRD results further support this.

\section{X-ray photoelectron spectroscopy (XPS) analysis}

$\mathrm{X}$-ray photoelectron spectroscopy (XPS) is very sensitive to the chemical composition and environment of the elements in a material. Figure 3a shows XPS survey spectra
$(0-1100 \mathrm{eV})$ of CZTS film calcinated at $400{ }^{\circ} \mathrm{C}$. The core level peaks corresponding to the elements copper $(\mathrm{Cu} 2 p)$, Zinc (Zn 2p), Tin (Sn 3d) and sulfur (S $2 p)$ can be visibly seen in the spectra. In addition, it also shows the presence of $\mathrm{C}$ peak as well as $\mathrm{O}$ peak at $\sim 285$ and $\sim 531 \mathrm{eV}$ respectively as impurities. These contaminants have also been identified in CZTS films by other workers [26]. The binding energy peak observed at $\sim 932.80 \mathrm{eV}$ corresponding to the $\mathrm{Cu} 2 \mathrm{p}_{3 / 2}$ core level in CZTS film [29]. Figure $3 \mathrm{~b}$ show high-resolution XPS spectrum of $\mathrm{Cu}$ $2 p$ consisting two narrow and symmetric peaks at $\sim 932.80$ and $\sim 952.46 \mathrm{eV}$, indicative of $\mathrm{Cu}(\mathrm{I})$ with a peak splitting of $19.66 \mathrm{eV}$. These results are well matched with the previously available data in the literature [30].The core line of $\mathrm{Zn}$ exhibited a doublet at $\sim 1022.17 \mathrm{eV}$ and $\sim 1045.25 \mathrm{eV}$ corresponding to $\mathrm{Zn} 3 d_{5 / 2}$ and $\mathrm{Zn} 3 d_{3 / 2}$ peaks with spinorbit separation $23.08 \mathrm{eV}$ (Fig. 3c) suggesting presences of $\mathrm{Zn}(\mathrm{II})$ in CZTS compound [31]. Figure 3d shows two peaks, one at $\sim 495.80 \mathrm{eV}$ corresponding to $\mathrm{Sn} 3 d_{3 / 2}$ core level in CZTS and other at $\sim 487.10 \mathrm{eV}$ from $\mathrm{Sn}$ in $\mathrm{SnS}_{2}$ phase [32] with spin-orbit separation $8.70 \mathrm{eV}$. Two S $2 p$ peaks are located at $\sim 161.5$ and $\sim 163.02 \mathrm{eV}$, respectively, showing a peak separation of $1.52 \mathrm{eV}$ (Fig. 3e), which is also consistent with literature value for a metal sulfide [33].Thus, XPS analysis confirms the formation of single phase CZTS films.

\section{Transmission electron microscopy (TEM) analysis}

Figure 4 shows detailed TEM analysis of CZTS film calcinated at $400{ }^{\circ} \mathrm{C}$. Figure 4 a shows low resolution TEM images of CZTS film calcinated at $400{ }^{\circ} \mathrm{C}$. As seen spherical CZTS nanoparticles having diameter in the range 5-25 nm and their agglomerates can also be clearly observed. The histogram of particle size distribution is plotted in Fig. 4b. The high-resolution TEM image shown in Fig. 4c indicates that CZTS nanoparticles are crystalline in nature. The inset figure shows the lattice fringes with the inter-planar distance of $0.31 \mathrm{~nm}$ which belong to (112) plane of kesterite-CZTS [34]. The electron diffraction pattern for the selected area (SAED) pattern shown in 

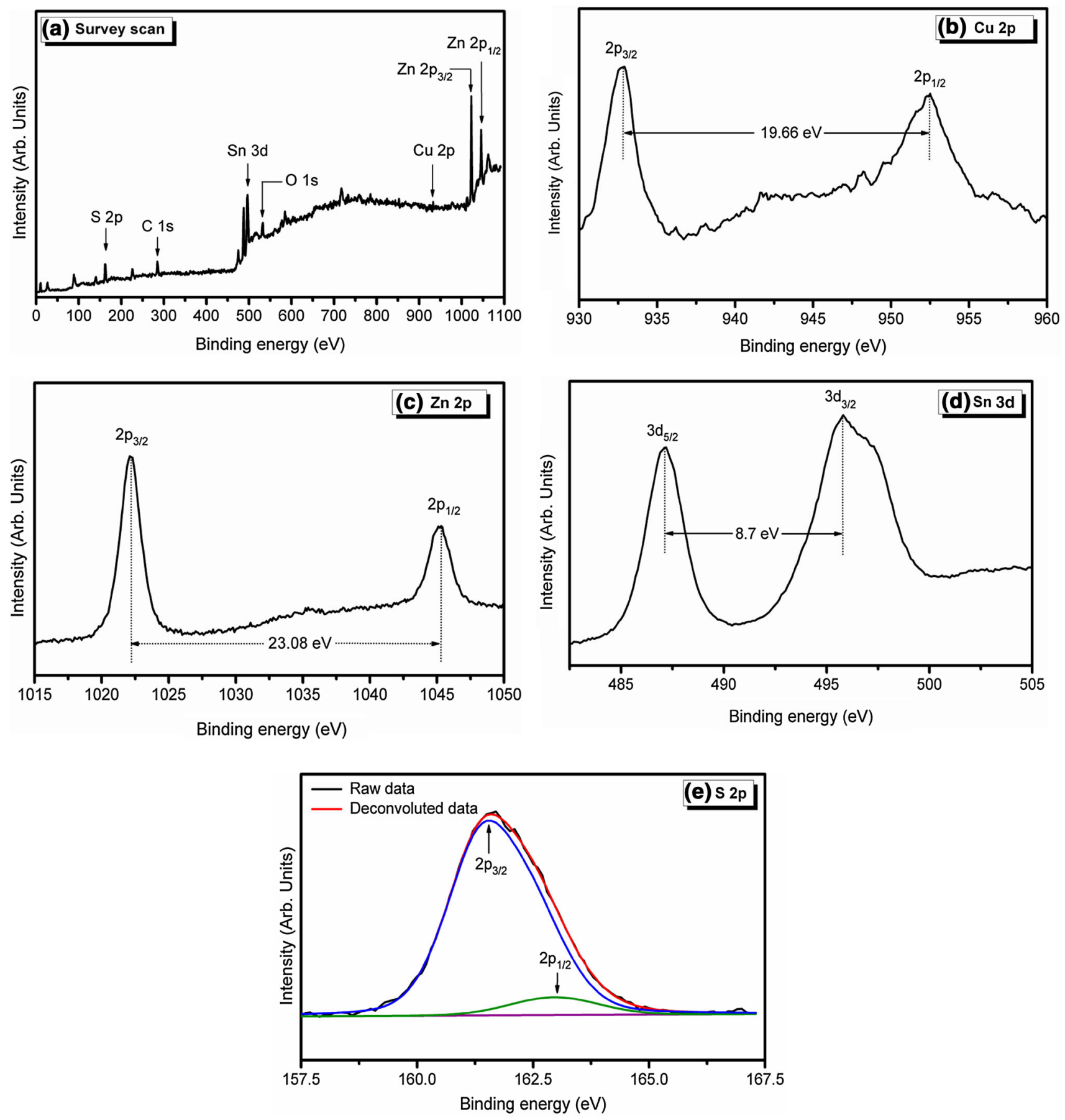

Fig. 3 Typical XPS spectra for CZTS film after calcination at $400{ }^{\circ} \mathrm{C}$. a Survey scan in the range $0-1100 \mathrm{eV}$. b High-resolution XPS spectrum of $\mathrm{Cu} 2 p$ in the range $930-960 \mathrm{eV}$. c Zn $2 p$ spectra in

Fig. $4 \mathrm{~d}$ is also in agreement with the low angle-XRD analysis, comprising of diffraction rings corresponding to the (112) and (200) planes of kesterite-CZTS. The diffraction ring corresponding to (224) plane is not clearly visible in SEAD pattern because of its weak intensity as seen in low angle-XRD pattern. the range $1015-1050 \mathrm{eV}$. d Sn $3 d$ spectra in the range $482.5-505 \mathrm{eV}$. e S $2 p$ spectra in the range $157.5-167.5 \mathrm{eV}$

\section{Atomic force microscopy (AFM) analysis}

Figure 5 shows surface topography of as-prepared and calcinated CZTS films investigated by non-contact atomic force microscopy (NC-AFM). The scan area for all AFM micrographs was $25 \mu \mathrm{m}^{2}\left(5 \times 5 \mathrm{~m}^{2}\right)$. NC-AFM micrograph of 

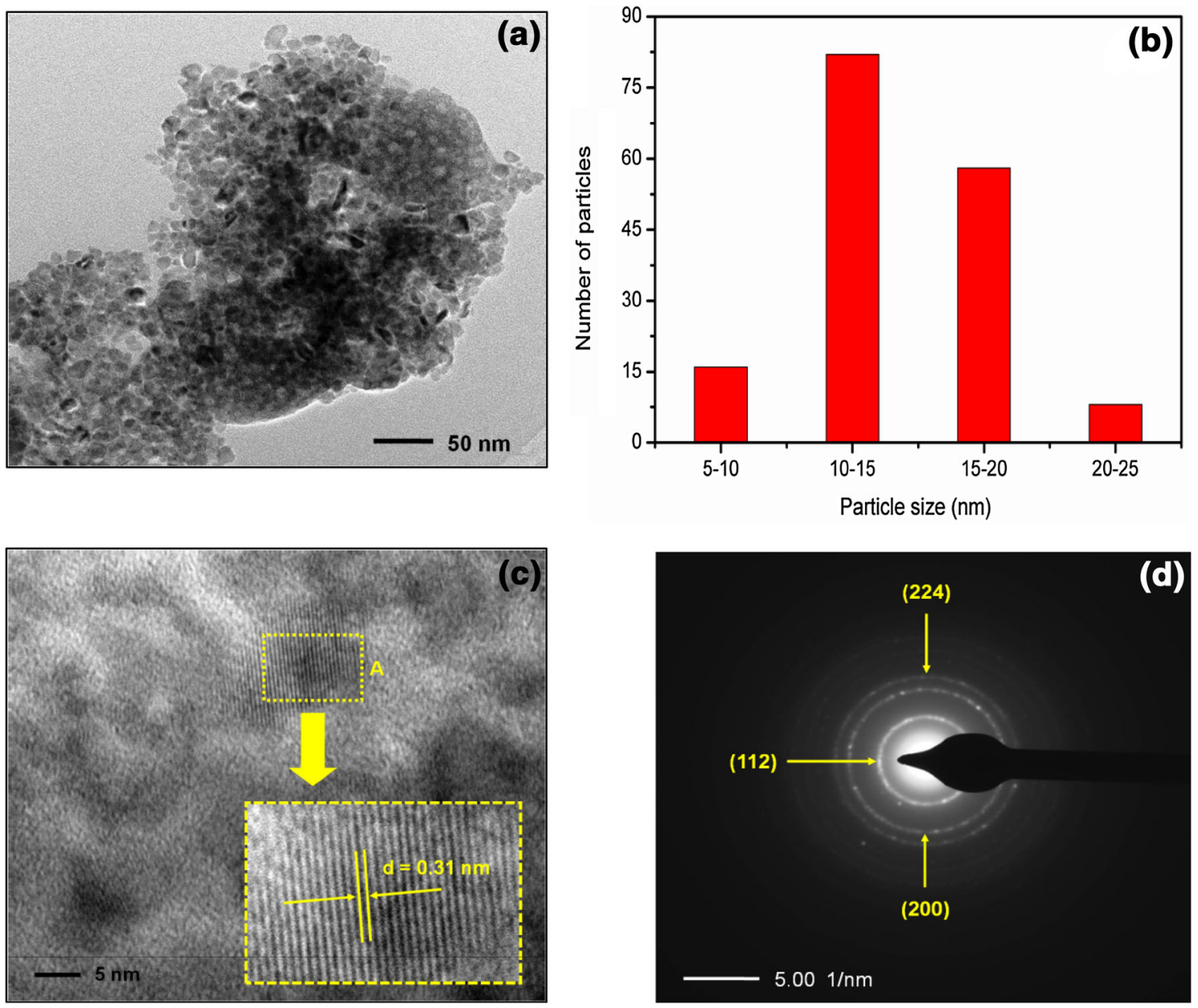

Fig. 4 a TEM image with low magnification, b particle size distribution histogram, representing particle size ranging from 5 to $25 \mathrm{~nm}$, c HR-TEM, demonstrating nanoparticles have lattice fringes

as-prepared CZTS film revealed textured surface with tiny uniform island-like topography. It has been reported that such topography originates from the island growth of the Volmer-Weber mode and the kinetic energy at low temperature is not sufficient for the coalescence of island-like crystallites [35]. The root mean square (rms) surface roughness of as-prepared CZTS film was found $\sim 0.32 \mathrm{~nm}$. The CZTS film calcinated at $200{ }^{\circ} \mathrm{C}$ (Fig. 5b) clearly indicate that these tiny textured island coalescence to form superstructure of smaller clusters with increased rms surface roughness to $\sim 0.76 \mathrm{~nm}$. The coalescence of textured island may occur due to increase in the surface mobility with increase in calcination temperature. Further increase in calcination temperature to $300{ }^{\circ} \mathrm{C}$ and $400{ }^{\circ} \mathrm{C}$ (Fig. 5(c, d) one can have observed that these smaller clusters of CZTS are bound together and formed into non-uniform larger clusters with enhanced surface roughness. Thus, CZTS films calcinated at $300{ }^{\circ} \mathrm{C}$ and $400{ }^{\circ} \mathrm{C}$ the rms surface roughness was found $\sim 0.60$ and $3.21 \mathrm{~nm}$ respectively. Therefore, from

with inter-planar distance of $0.31 \mathrm{~nm}$, and d SAED pattern of concentric rings correspond to three major peaks in XRD of KesteriteCZTS nanoparticles

AFM analysis it has been concluded that with increase in calcination temperature the particle size and surface roughness of CZTS film increases.

\section{UV-Visible spectroscopy analysis}

The optical properties of as-deposited and calcinated CZTS films were investigated from UV-Visible spectroscopy. The optical absorption coefficient $(\alpha)$ can be calculated from the transmittance $(T)$ and reflection $(R)$ of the films with the formula [36],

$\alpha=\frac{1}{d} \ln \left(\frac{T}{1-R}\right)$

where $d$ is the thickness of the films. Figure 6 a display the variation of absorbance for as-deposited and calcinated CZTS thin films. The optical absorption coefficient after calcinations CZTS films was found $>10^{4} \mathrm{~cm}^{-1}$ in the visible region indicating a direct bandgap characteristic of CZTS films. 
Fig. 5 Two-dimensional (2D) AFM images of as-deposited and calcinated CZTS films. The scan area is $25 \mu \mathrm{m}^{2}(5 \times$ $5 \mu \mathrm{m}^{2}$ )
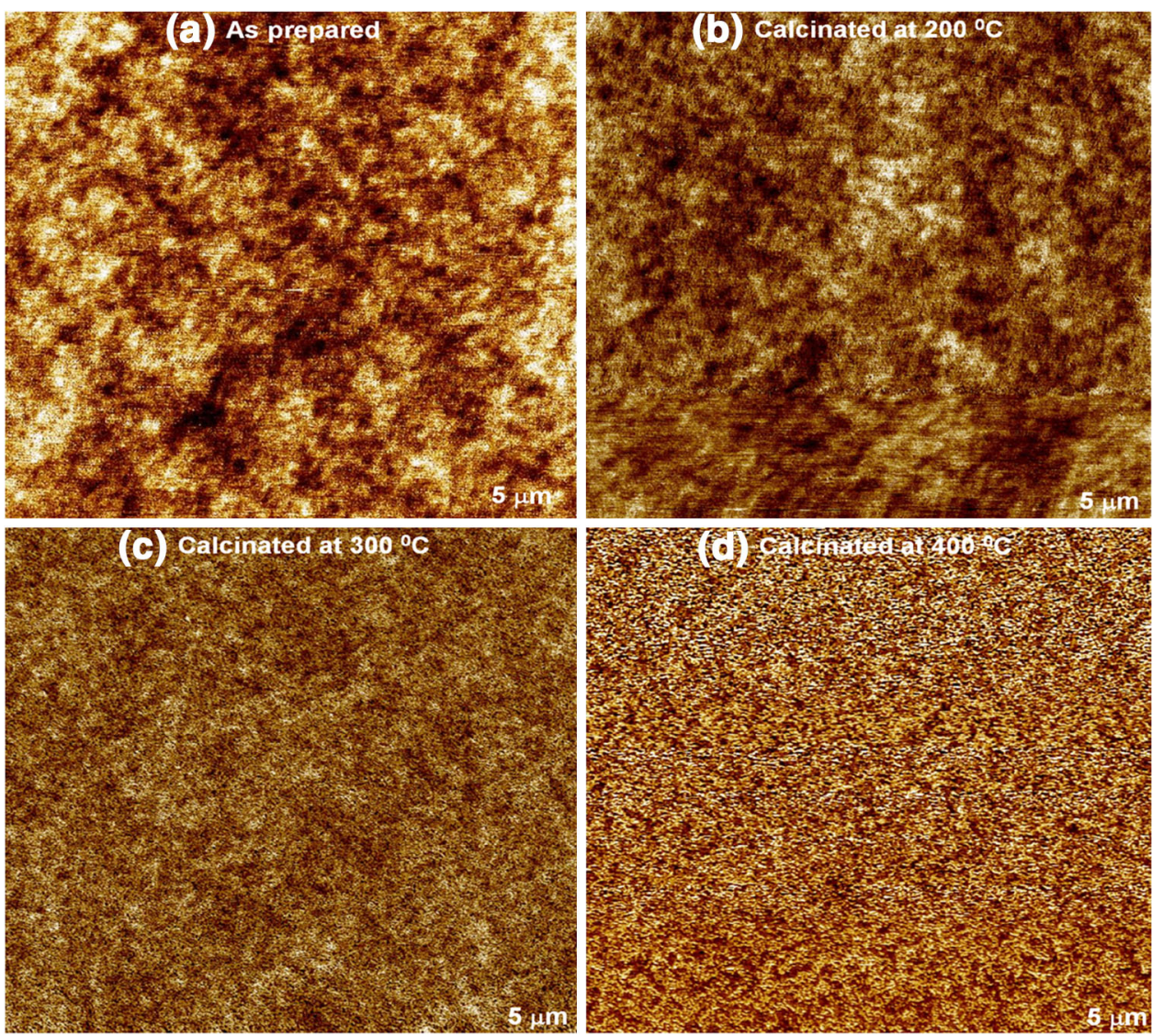

In the direct transition semiconductor, the optical energy bandgap $\left(E_{\text {opt }}\right)$ and the optical absorption coefficient $(\alpha)$ are related by [37],

$$
(\alpha E)^{1 / 2}=B^{1 / 2}\left(E-E_{\text {opt }}\right)
$$

where $\alpha$ is the absorption coefficient, $B$ is the optical density of state and $E$ is the photon energy. Therefore, optical bandgap can obtained by extrapolating the tangential line to the photon energy $(E=h v)$ axis in the plot of $(\alpha h v)^{2}$ versus photon energy (hv). Figure 6(b) shows plot of $(\alpha h v)^{2}$ versus photon energy (hv) (Tauc plot) of asdeposited and calcinated CZTS films. As seen from the figure with increase in calcination temperature optical bandgap of CZTS films decreases from 1.91 to $1.59 \mathrm{eV}$. The obtained bandgap values are consistent with the bulk value of CZTS (1.45-1.90 eV) [38]. The main factor that affect the band gap of CZTS films are the average grain size [39] and presence of multiple phases of CZTS in the films [40]. As revealed from our low angle-XRD (Fig. 1) and Raman spectroscopy (Fig. 2) analysis the existence of multiple phases CZTS in the films are ruled out. Therefore, decrease in optical bandgap of CZTS films can attribute to increase in average grain size. Graphical presentation of dependence bandgap on average grain size is shown in Fig. 7. The optical bandgap of CZTS film calcinated at
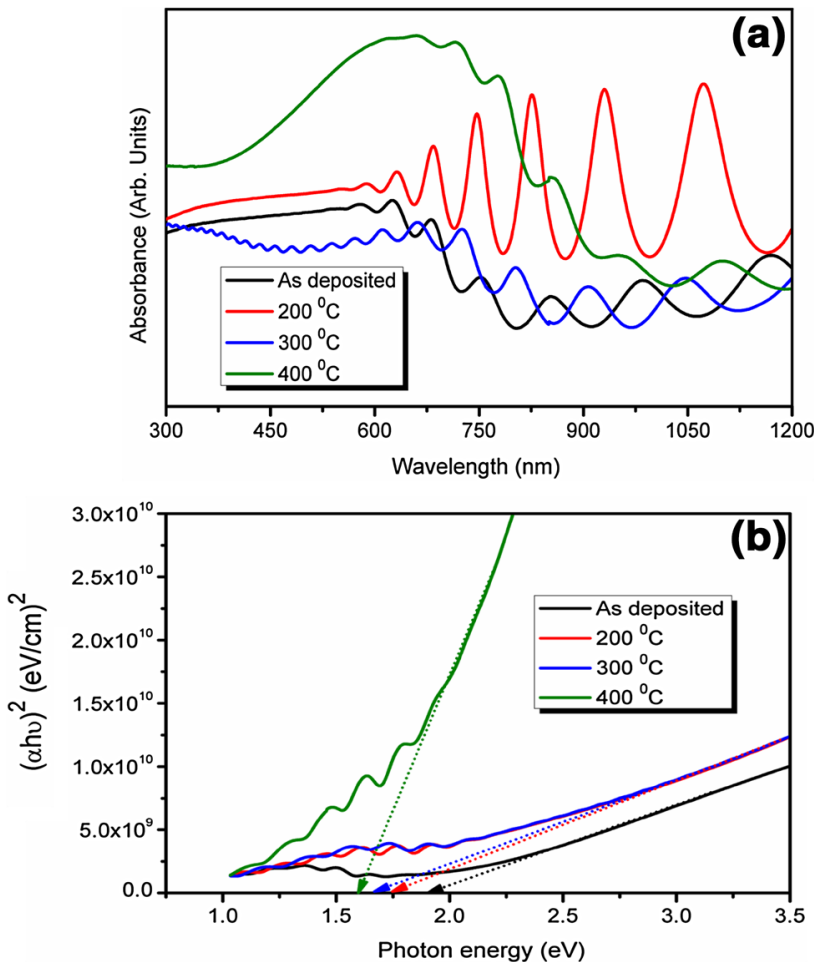

Fig. 6 a UV-Visible NIR spectra recorded showing absorbance versus wavelength plot for CZTS thin films. b Plot of $(\alpha h v)^{2}$ versus photon energy (hv) to determine optical bandgap for as-deposited and calcinated CZTS films 
Fig. 7 Graphical presentation of dependence bandgap on average grain size of asdeposited and calcinated CZTS films

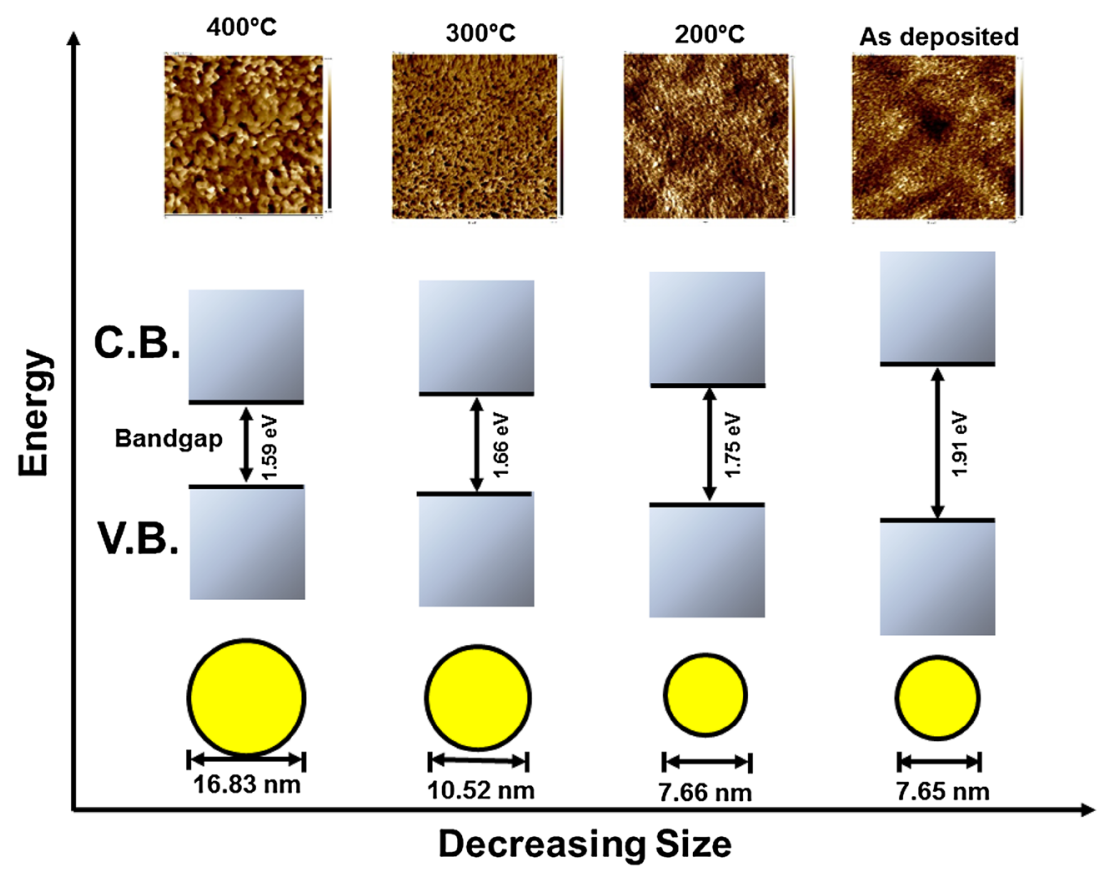

$400{ }^{\circ} \mathrm{C}$ is $\sim 1.59 \mathrm{eV}$ which is quite close to the optimum value bandgap for photovoltaic solar conversion in the visible region of solar spectrum.

\section{Photo response measurement}

Figure 8 shows the current versus time (I-t) plot as-deposited and calcinated CZTS films at constant $0.2 \mathrm{~V}$ bias voltage under dark and illumination conditions. For electrical properties measurement we have used samples of area $0.5 \mathrm{~cm}^{2}$. As seen there is significant improvement in the current with increase in calcinations temperature. The improvement in electrical properties may attribute to improvement in crystalline nature, texture, grain size of CZTS films with increase in calcinations temperature. Such

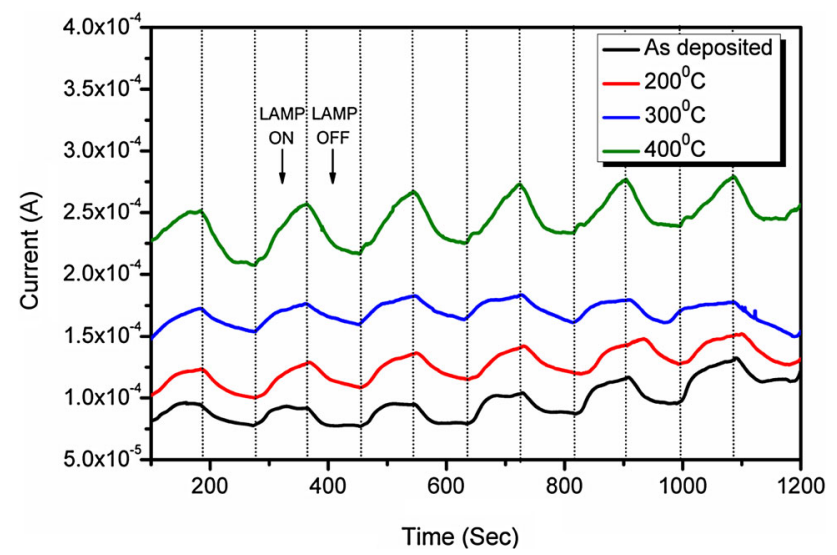

Fig. 8 Current versus time (I-t) plot of as-deposited and calcinated CZTS films at constant $0.2 \mathrm{~V}$ bias voltage for $60 \mathrm{~s}$ illuminations and for $60 \mathrm{~s}$ dark condition larger grains CZTS thin films can be useful as an absorber layer for the improvement in photoelectric conversion efficiency because larger grain sized which can reduce the recombination rate of photo-generated charge carriers [41].

\section{Conclusion}

In summary, nanocrystalline CZTS films have been prepared by home-made RF magnetron sputtering technique. Influence of calcination temperature in $\mathrm{Ar}$ atmosphere on structural, morphological, electrical and optical properties on CZTS films has been investigated. Formation of CZTS has been confirmed by x-ray photoelectron spectroscopy (XPS) whereas formation of Kesterite-CZTS films has been confirmed by X-ray diffraction (XRD), transmission electron microscopy (TEM) and Raman spectroscopy. We found that the calcination process has a great influence on growth and nucleation of grains. XRD analysis revealed that the crystallinity and average grain size increases with increase in calcination temperature. Raman spectroscopy analysis show shifting of Raman peak shift towards lower wavenumber with increase in calcination temperature. The presence of internal compressive stress and shrinking of substrate during cooling may responsible for shifting of Raman peak towards lower wavenumber. However, shrinking of substrate while cooling has not been verified experimentally. Detail surface study (morphology and topology) reveal that CZTS thin films have densely packed and a highly interconnected network of grains with large area $\left(4 \mathrm{~cm}^{2}\right)$. AFM show significant difference in surface 
topography of CZTS films with change in calcination temperature. Increase in calcination temperature show increase in rms and average surface roughness of the CZTS films. UV-Visible spectroscopy analysis revealed that the absorption coefficient of as-deposited and calcinated CZTS films are in the range $10^{4}-10^{5} \mathrm{~cm}^{-1}$ in the visible region. The bandgap show decreasing trend with increase in calcination temperature $(1.91-1.59 \mathrm{eV})$. The bandgap of CZTS film annealed at $400{ }^{\circ} \mathrm{C}$ was found $\sim 1.59 \mathrm{eV}$ which is quite close to the optimum value for photovoltaic solar conversion in the visible region of solar spectrum. It is found that the photo response depends upon the grain size effect, whereas photo response increases with the increase of the grain size. Employment these films as an absorber layer in CZTS solar cells can improve the conversion efficiency by reducing recombination rate of photo-generated charge carriers due to increased grain size.

Acknowledgement Mr. Sachin Rondiya is grateful to Dr. Babasaheb Ambedkar Research and Training Institute (BARTI), Pune for research fellowship and financial assistance and INUP IITB project sponsored by DeitY, MCIT, Government of India. Mr. Avinash Rokade is grateful to MNRE, New Delhi for National Renewable Energy (NRE) fellowship. One of the authors Dr. Sandesh Jadkar is thankful to University Grants Commission, New Delhi for special financial support under UPE program. Mr. Ashok Jadhavar is thankful to BARC-SSPU program for financial support.

Open Access This article is distributed under the terms of the Creative Commons Attribution 4.0 International License (http:// creativecommons.org/licenses/by/4.0/), which permits unrestricted use, distribution, and reproduction in any medium, provided you give appropriate credit to the original author(s) and the source, provide a link to the Creative Commons license, and indicate if changes were made.

\section{References}

1. Kalowekamo, J., Baker, E.: Estimating the manufacturing cost of purely organic solar cells. Sol. Energy 83, 1224-1231 (2009)

2. Steinhagen, C., Panthani, M.G., Akhavan, V., Goodfellow, B., Koo, B., Korgel, B.A.: Synthesis of $\mathrm{Cu}_{2} \mathrm{ZnSnS}_{4}$ nanocrystals for use in low-cost photovoltaics. J. Amer. Chem. Soc. 131, 12554-12555 (2009)

3. Tanaka, K., Oonuki, M., Moritake, N., Uchiki, H.: $\mathrm{Cu}_{2} \mathrm{ZnSnS}_{4}$ thin film solar cells prepared by non-vacuum processing. Sol. Energy Mater. Sol. Cells 93, 583-587 (2009)

4. Katagiri, H., Jimbo, K., Maw, W.S., Oishi, K., Yamazaki, M., Araki, H., Takeuchi, A.: Development of CZTS-based thin film solar cells. Thin Solid Films 517, 2455-2460 (2009)

5. Guo, Q., Hillhouse, H.W., Agrawal, R.: Synthesis of $\mathrm{Cu}_{2} \mathrm{Zn} \mathrm{Sn}$ $\mathrm{S}_{4}$ nanocrystal ink and its use for solar cells. J. Amer. Chem. Soc. 131, 11672-11673 (2009)

6. Henry, C.H.: Limiting efficiencies of ideal single and multiple energy gap terrestrial solar cells. J. Appl. Phys. 51, 4494-4500 (1980)

7. Wang, W., Winkler, M.T., Gunawan, O., Gokmen, T., Todorov, T.K., Zhu, Y., Mitzi, D.B.: Device characteristics of CZTSSe thin-film solar cells with $12.6 \%$ efficiency. Adv. Energy Mater. 4, 1301465 (2014)

8. Zeng, X., TaiK, F., Zhang, T., Ho, C., Chen, X., Huan, A., Sum, T.C., Wong, L.H.: $\mathrm{Cu}_{2} \mathrm{Zn} \mathrm{Sn}$ (S, Se) 4 kesterite solar cell with $5.1 \%$ efficiency using spray pyrolysis of aqueous precursor solution followed by selenization. Sol. Energy Mater. Sol. Cells 124, 55-60 (2014)

9. Fernandes, P.A., Salomé, P.M.P., Cunha, A.F.: Growth and Raman scattering characterization of $\mathrm{Cu}_{2} \mathrm{ZnSnS}_{4}$ thin films. Thin Solid Films 517, 2519-2523 (2009)

10. Tanaka, K., Moritake, N., Uchiki, H.: Preparation of $\mathrm{Cu}_{2} \mathrm{Zn} \mathrm{Sn}$ $\mathrm{S}_{4}$ thin films by sulfurizing sol-gel deposited precursors. Sol. Energy Mater. Sol. Cells 91, 1199-1201 (2007)

11. Swami, S.K., Kumar, A., Dutta, V.: Deposition of kesterite $\mathrm{Cu}_{2}$ $\mathrm{Zn} \mathrm{Sn} \mathrm{S}_{4}$ (CZTS) thin films by spin coating technique for solar cell application. Energy Procedia. 33, 198-202 (2013)

12. Todorov, T.K., Reuter, K.B., Mitzi, D.B.: Highefficiency solar cell with earth-abundant liquid-processed absorber. Adv. Mater. 22, E156-E159 (2010)

13. Mali, S., Patil, P., Hong, C.: Low-cost electrospun highly crystalline kesterite $\mathrm{Cu}_{2} \mathrm{Zn} \mathrm{Sn} \mathrm{S}_{4}$ nanofiber counter electrodes for efficient dye-sensitized solar Cells. ACS Appl. Mater. Interfaces. 6, 1688-1696 (2014)

14. Mali, S.S., Shinde, P.S., Betty, C.A., Bhosale, P.N., Oh, Y.W., Patil, P.S.: Synthesis and characterization of $\mathrm{Cu}_{2} \mathrm{Zn} \mathrm{Sn} \mathrm{S}_{4}$ thin films by SILAR method. J. Phys. Chem. Solids 73(6), 735-740 (2012)

15. Dhakal, T.P., Peng, C.Y., Tobias, R.R., Dasharathy, R., Westgate, C.R.: Characterization of a CZTS thin film solar cell grown by sputtering method. Sol. Energy 100, 23-30 (2014)

16. Lee Y. S., Gershon T., Gunawan O., Todorov T. K., Gokmen T., Virgus Y., Guha S.: Adv. Energy Mater. 5, 1401372-1-5 (2015)

17. Sun, L., He, J., Kong, H., Yue, F., Yang, P., Chu, J.: Structure, composition and optical properties of $\mathrm{Cu}_{2} \mathrm{Zn} \mathrm{Sn} \mathrm{S}_{4}$ thin films deposited by pulsed laser deposition method. Sol. Energy Mater. Sol. Cells 95, 2907-2913 (2011)

18. Wang, J., Li, S., Cai, J., Shen, B., Ren, Y., Qin, G.: Cu2ZnSnS4 thin films: facile and cost-effective preparation by RF-magnetron sputtering and texture control. J. Alloys Compd. 552, 418-422 (2013)

19. Seboui, Z., Gassoumi, A., Cuminal, Y., Turki, N.K.: The postgrowth effect on the properties of $\mathrm{Cu}_{2} \mathrm{Zn} \mathrm{Sn} \mathrm{S}_{4}$ thin films. J. Renew. Sus. Energy 7, 011203 (2015)

20. Ericson, T., Scragg, J.J., Kubart, T., Törndahl, T., Björkman, C.P.: Annealing behavior of reactively sputtered precursor films for $\mathrm{Cu}_{2} \mathrm{Zn} \mathrm{Sn} \mathrm{S}$ solar cells. Thin Solid Films 535, 22-26 (2013)

21. Surgina, G.D., Nevolin, V.N., SipayloI, P., Teterin, P.E., Medvedeva, S.S., Lebedinsky, Y.Y., Zenkevich, A.V.: Effect of annealing on structural and optical properties of $\mathrm{Cu}_{2} \mathrm{Zn} \mathrm{Sn} \mathrm{S}_{4}$ thin films grown by pulsed laser deposition. Thin Solid Films 594, 74-79 (2015)

22. Vanalakar, S.A., Shin, S.W., Agawane, G.L., Suryawanshi, M.P., Gurav, K.V., Patil, P.S., Kim, J.H.: Effect of post-annealing atmosphere on the grain-size and surface morphological properties of pulsed laser deposited CZTS thin films. Ceram. Int. 40, 15097-15103 (2014)

23. Liu, R., Tan, M., Zhang, X., Chen, J., Song, S., Zhang, W.: Impact of sol-gel precursor treatment with preheating temperature on properties of $\mathrm{Cu}_{2} \mathrm{Zn} \mathrm{Sn} \mathrm{S}_{4}$ thin film and its photovoltaic solar cell. J. Alloys Compd. 655, 124-129 (2016)

24. Cullity, B.D., Stock, S.: Elements of X-ray Diffraction, 3rd edn. Princeton Hall, New Jersey (2001)

25. Girija, K., Thirumalairajan, S., Mohan, S., Chandrasekaran, J.: Structural, morphological and optical studies of CdSe thin films from ammonia bath. Chalcog. Lett. 6(8), 351-357 (2009) 
26. Su, Z., Sun, K., Han, Z., Cui, H., Liu, F., Lai, Y., Li, J., Hao, X., Liu, Y., Green, M.A.: Fabrication of $\mathrm{Cu}_{2} \mathrm{Zn} \mathrm{Sn} \mathrm{S} \mathrm{S}_{4}$ solar cells with $5.1 \%$ efficiency via thermal decomposition and reaction using a non-toxic sol-gel route. J. Mate. Chem. 2(2), 500-509 (2014)

27. Yoo, H., Kim, J.: Comparative study of $\mathrm{Cu}_{2} \mathrm{Zn} \mathrm{Sn} \mathrm{S}_{4}$ film growth. Sol. Energy Mater. Sol. Cells 95(1), 239-244 (2011)

28. Khadka, D.B., Kim, J.: Band gap engineering of alloyed $\mathrm{Cu}_{2} \mathrm{Zn}$ $\mathrm{Ge}_{\mathrm{x}} \mathrm{Sn}_{1-\mathrm{x}} \mathrm{Q} 4(\mathrm{Q}=\mathrm{S}, \mathrm{Se})$ films for solar cell. J. Phys. Chem. C 119(4), 1706-1713 (2015)

29. Moulder, J.F., Chastain, J.: Handbook of x-ray photoelectron spectroscopy. In: Eden, P. (ed.) A reference book of standard spectra for identification and interpretation of XPS data. PerkinElmer Corp, Chanhassen (1992)

30. Zou, C., Zhang, L., Lin, D., Yang, Y., Li, Q., Xu, X., Chen, X., Huang, S.: Facile synthesis of $\mathrm{Cu}_{2} \mathrm{Zn} \mathrm{Sn} \mathrm{S}_{4}$ nanocrystals. Cryst. Eng. Comm. 13(10), 3310-3313 (2011)

31. Sun, Y., Zhang, Y., Wang, H., Xie, M., Zong, K., Zheng, H., Shu, Y., Liu, J., Yan, H., Zhu, M.: Novel non-hydrazine solution processing of earth-abundant $\mathrm{Cu}_{2} \mathrm{Zn} \mathrm{Sn}(\mathrm{S}, \mathrm{Se})_{4}$ absorbers for thin-film solar cells. J. Mate. Chem. A 1(23), 6880-6887 (2013)

32. Khélia, C., Boubaker, K., Ben, Nasrallah T., Amlouk, M., Belgacem, S.: Morphological and thermal properties of $\beta-\mathrm{SnS}_{2}$ sprayed thin films using Boubaker polynomials expansion. J. Alloys Compd. 477, 461-467 (2009)

33. Su, Z., Sun, K., Han, Z., Liu, F., Lai, Y., Li, J., Liu, Y.: Fabrication of ternary $\mathrm{Cu}-\mathrm{Sn}-\mathrm{S}$ sulfides by a modified successive ionic layer adsorption and reaction (SILAR) method. J. Mate. Chem. 22(32), 16346-16352 (2012)
34. Lu, X., Zhuang, Z., Peng, Q., Li, Y.: Wurtzite $\mathrm{Cu}_{2} \mathrm{ZnSnS}_{4}$ nanocrystals: a novel quaternary semiconductor. Chem. Comm. 47(11), 3141-3143 (2011)

35. Shah, N., Panchal, C., Kheraj, V., Ray, J., Desai, M.: Growth, structural and optical properties of copper indium diselenide thin films deposited by thermal evaporation method. Sol. Energy 83(5), 753-760 (2009)

36. Muth, J.F., Lee, J.H., Shmagin, I.K., KolbasH, R.M., Casey, C., Keller, B.P., Mishra, U.K., Den Baars, S.P.: Absorption coefficient, energy gap, exciton binding energy, and recombination lifetime of $\mathrm{GaN}$ obtained from transmission measurements. Appl. Phys. Lett. 71(18), 2572-2574 (1997)

37. Tauc, J.: Absorption edge and internal electric fields in amorphous semiconductors. Mater. Res. Bull. 5(8), 721-729 (1970)

38. Katagiri, H.: $\mathrm{Cu}_{2} \mathrm{ZnSnS}_{4}$ thin film solar cells. Thin Solid Films 480, 426-432 (2005)

39. Liu, W., Guo, B., Wu, X., Zhang, F., Mak, C., Wong, K.: Facile hydrothermal synthesis of hydrotropic $\mathrm{Cu}_{2} \mathrm{ZnSnS}_{4}$ nanocrystal quantum dots: band-gap engineering and phonon confinement effect. J. Mate. Chem. A 1(9), 3182-3186 (2013)

40. Shin, S.W., Pawar, S.M., Park, C.Y., Yun, J.H., Moon, J.H., Kim, J.H., Lee, J.Y.: Studies on $\mathrm{Cu}_{2} \mathrm{ZnSnS}_{4}$ (CZTS) absorber layer using different stacking orders in precursor thin films. Sol. Energy Mater. Sol. Cells 95(12), 3202-3206 (2011)

41. Persson, C.: Electronic and optical properties of $\mathrm{Cu}_{2} \mathrm{Zn} \mathrm{Sn} \mathrm{S} \mathrm{S}_{4}$ and $\mathrm{Cu}_{2} \mathrm{Zn} \mathrm{Sn} \mathrm{Se}{ }_{4}$. J. Appl. Phys. 107, 710 (2010) 